\title{
Educação de adultos presos
}

Manoel Rodrigues Portugues

FUNAP - Sistema Penitenciário do Estado de São Paulo

Resumo

Este artigo apresenta uma reflexão acerca das possibilidades e contradições da inserção da educação escolar nos programas de reabilitação do sistema penal do estado de São Paulo.

As prisões, suas normas, procedimentos e valores observam a absoluta primazia na dominação e no controle da massa encarcerada. Decorre que a manutenção da ordem e disciplina internas são transfiguradas pelo fim precípuo da organização penal. Os programas e atividades considerados "reeducativos" inserem-se nesta lógica de funcionamento, pautando suas ações e finalidades pela necessidade de subjugar os sujeitos punidos, adaptando-os ao sistema social da prisão. Contudo, a resistência prisioneira ao controle é patente.

A educação, de forma alguma, permanece neutra nesse processo de subjugação e resistência. Seus pressupostos metodológicos e suas práticas cotidianas podem contribuir para a sedimentação da escola enquanto recurso ulterior de preservação e formação dos sujeitos, nos interstícios dos processos de dominação.

0 artigo procura delinear as possibilidades para que as prerrogativas da gestão penitenciária não intervenham nas práticas educativas, prescrevendo suas ações, de forma a constituir uma alternativa para que os sujeitos encarcerados, mesmo nas condições hostis em que se encontram, disponham de oportunidade ulterior para produzir cultura e conhecimento, indicando caminhos rumo ao seu desenvolvimento humano; que Ihes proporcione designar o mundo presente e futuro, num ato contínuo de criação e recriação, significação e ressignificação.

Palavras-chave

Educação de adultos presos - Sistema penal e educação - Reabilitação penal.

Correspondência: 


\section{Education of adults in prison}

Manoel Rodrigues Portugues

FUNAP - Sistema Penal de São Paulo

\section{Abstract}

This article presents a reflection about the possibilities and contradictions of the insertion of school education in the rehabilitation programs of the State of São Paulo Penal System.

Prisons, their norms, procedures and values adhere to the absolute primacy of domination and control of the incarcerated mass. It follows that the maintenance of internal order and discipline are transfigured into the penal organization's primary purpose. The programs and activities regarded as "re-educative" fit into this working logic, guiding their actions and objectives by the need to subjugate the punished persons, adjusting them to the social system of prison. The inmate's resistance to control is, how ever, patent. Education does not, by any means, remain neutral in this process (struggle) of subjugation and resistance. Its methodological assumptions and its daily practices can contribute to establish school as the succeeding resource in the preservation and development of persons, in the interstices of the domination process.

The article tries to outline some possibilities of education so that the prerogatives of penal management do not shatter educative practices, prescribing its actions. In doing that, it seeks to indicate an alternative so that incarcerated persons, even under the hostile conditions they face, have the later opportunity to produce culture and knowledge, showing paths to a human development that allows them to designate the world present and future, in a continuous act of creation and re-creation, signification and re-signification.

Keywords

Adult education - Penal system - Rehabilitation.

\footnotetext{
Correspondence:
}

Manoel Rodrigues Portugues

Rua Dr. Vila Nova, 268

1222-020 - São Paulo - SP

E-mail: maneducult@ig.com.br 
As prisões mostram-se presentes à sociedade, de forma mais abrangente, em momentos em que sua rotina institucional é fortemente abalada, caso de rebeliões, motins, fugas e massacres de prisioneiros. Uma variada gama de sensações, sentimentos e percepções se prolifera, configurando reações de repulsa, ódio, vingança, curiosidade, morbidez, compaixão e até solidariedade.

Afora esses momentos, vigora com maior intensidade um distanciamento da questão penitenciária, caracterizando uma dupla exclusão: de um lado a prisão, seus corpos dirigente e funcional que imprimem uma forma de gestão autônoma e autocentrada, marcada pela invisibilidade e impenetrabilidade, procurando manter-se independente em relação ao aparato do Estado e à influência da sociedade; por outro lado, a própria sociedade, que procura distanciar-se dessa realidade, exigindo da prisão apenas 0 aspecto referente à segurança do cidadão, portanto, sem fugas e desordens (Fischer, 1996).

As práticas ef etivas que regulam o cotidiano das prisões são absolutamente desconhecidas pela sociedade, mantendo-se opacas até mesmo com relação aos órgãos públicos que Ihes são afins.

Embora exista a Vara de Execuções Criminais e a Coordenadoria dos Estabelecimentos Penitenciários do Estado, aos quais os Estabelecimentos Penais estão ligados legal e hierarquicamente, 0 ordenamento nessas instituições tem autonomia, uma vez que suas práticas cotidianas escapam às esferas superiores. (Castro, 1991, p. 61)

A sociedade civil, ao dirigir o foco de atenção somente para o ápice da crise institucional da organização penitenciária, evidencia um descaso em relação à reabilitação dos indivíduos punidos. Atesta-se, nesse sentido, a impressão de que as prisões constituem-se mormente como uma "universidade do crime", na qual os prisioneiros aprimoram uma condu- ta criminosa e planos delituosos, ao invés de ser uma instituição (re)educativa. "Reconhecida, inclusive pelo próprio poder público, como espetáculo da violência e a 'universidade do crime', dela não se pode esperar que recupere; contudo, que reproduza a delinqüência" (Castro et al., 1984, p. 106).

Punição/contenção ou reabilitação? Definitivamente a correlação de forças que disputam o controle e a hegemonia na formulação de políticas públicas penitenciárias encontra-se nesses dois pólos que concebem a finalidade da pena de privação da liberdade. 0 conflito entre eles não é uma ocorrência ocasional ou fortuita. Antes é parte constitutiva da prisão e de sua organização.

Ao longo de sua existência, invariavelmente, se sobressai a função de punir, afirmando os procedimentos que the são necessários, os quais culminam por transformar a manutenção da ordem interna, a vigilância, a disciplina, a segurança, no fim precípuo da organização penal. Isso não significa que os programas de reabilitação do sistema penal são ausentes ou inexistentes, mas que estão inseridos nesta lógica, cuja contenção transfigura-se enquanto aspecto central da prisão, afiançando-a:

Entre o discurso oficial e o modo de vida instaurado pelas práticas de ressocialização próprias da prisão, estabelece-se um hiato: embora se pretenda que o aprimoramento técnico da equipe dirigente possibilite a humanização do tratamento, as técnicas "criminiátricas" adotadas põem à mostra seu lado reverso, ao exercerem efeitos tão contraditórios quanto inesperados. A prioridade conferida à ordem e à disciplina, modo pelo qual, em última instância, se acredita poder concretizar 0 ideal de defesa social preconizado pelo Código Criminal, impõem barreiras intransponíveis. No dilema entre punir e recuperar, vence aquilo que parece ser 0 termo negativo da equação: a prisão limita-se a punir. (Castro et al., 1984, p. 112) 
À existência mesmo da prisão, é limiar esse embate sobre suas finalidades. Basilar de sua constituição, o dilema que se lhe apresenta não pode, de forma alguma, ser superado, pois significaria, no limite, acometer a própria pena de encarceramento. Seus fins confessos, reabilitar e punir, fornecem os pilares para sua sustentação. Subjugar um ou outro, portanto, denotaria sua derrocada enquanto a forma por excelência de combate à criminalidade. São duas forças que disputam o controle e a prioridade na formulação das políticas públicas penitenciárias e na organização de seus procedimentos de gestão, que não podem prescindir uma da outra, sob o risco de ambas deixarem de existir.

Afinal, no Estado democrático de direito o que possibilita o poder discricionário de punir é a finalidade de reabilitação que se atribui à prisão (Rodrigues, 1999). Entretanto, em sintonia com as expectativas sociais acerca da pena de encarceramento, a organização penitenciária limita-se à contenção e à punição:

\section{A despeito de propósitos reformadores e resso- cializadores embutidos na fala dos governantes e na conviç̧ão de homens aos quais está incum- bida a tarefa de administrar massas carcerárias, a prisão não consegue dissimular seu avesso: 0 de ser aparelho exemplarmente punitivo. (Ador- no, 1991b, p. 70)}

A operação penitenciária, sua organização, procedimentos, normas, programas e atividades, configurados para proporcionar a reabilitação dos criminosos, culminam por convergir suas ações para aprimorar a contenção e o controle da massa encarcerada.

Arrolada como aspecto central na transformação de criminosos em não-criminosos encontra-se a atividade de educação. Emerge, assim, o problema crucial deste artigo, qual seja: quais são as possibilidades para se desenvolver um processo educativo num ambiente altamente hostil como 0 das prisões, cuja primazia organizacional recai nos aspectos $d a$ punição, de controle e da vigilância?
A administração penitenciária no estado de São Paulo

Antes de adentrar à análise dos programas de reabilitação em geral, e de educação em particular, é necessário, mesmo que de forma sucinta, apresentar a administração penitenciária em São Paulo, considerando a cisão entre estabelecimentos que se destinam à reabilitação dos indivíduos e aqueles cuja finalidade é meramente de contenção.

Identificados com esta última, estão os distritos policiais e os "cadeiões", instituições submetidas à Secretaria de Estado da Segurança Pública. Destinam-se ao encarceramento provisório: indivíduos presos em flagrante delito, pronúncia ou sentença condenatória recorrível no aguardo de sua sentença e os presos por medida preventiva, devendo permanecer separados dos demais (Lei de Execução Pena, Artigo 2\%).

Aos indivíduos já condenados à pena de encarceramento apresentam-se os estabelecimentos penais pertencentes à Secretaria de Estado da Administração Penitenciária, aos quais se atribui a finalidade de reabilitar os criminosos.

Um grave problema que se verifica na administração penal paulista é o da transformação dos distritos policiais e "cadeiões", com caráter eminentemente provisório, em estabelecimentos para o cumprimento da pena de reclusão, sem, contudo, possuírem estrutura física, humana e organizacional arrogadas como necessárias à reabilitação dos condenados.

0 estado de São Paulo possui pouco mais de 80 mil encarcerados, sendo 62,5\% (50 mil) na Secretaria da Administração Penitenciária e 31.724 nos distritos e cadeiões, dos quais 11.441 (36\%) em situação irregular, ou seja, já condenados pela J ustiça (Folha de S. 
Paulo, 20/agosto/2000, p. 3-4). Esse contingente bastante significativo de encarcerados encontra-se em condições absolutamente subumanas. A esse fato, por si só bastante grave, acrescenta-se um outro, que é o de policiais serem transformados em carcereiros. Desde o final do século XVIII e início do XIX, a justiça criminal passou por processos de racionalização, que culminaram numa complexa mutação no que concerne ao direito de punir (Fischer e Abreu, 1987). Ao objetivo de proteção da sociedade acresceu-se o de reformar o indivíduo, procedendo-se para tanto à separação entre os atos de prender, julgar e punir. Em face deste objetivo, constituiu-se um saber especializado (técnico-científico) sobre esses indivíduos punidos, no sentido de transformá-los: psiquiatria, psicologia, medicina, pedagogia, arquitetura, assistência social e sociologia tiveram, no sistema penitenciário, seu ponto convergente, tornando-o uma "empresa para modificar as pessoas" (Foucault, 1986, p. 196) - e, simultaneamente, seu pólo difusor, construindo pressupostos que passaram a ser válidos para todo o corpo social.

Por conseguinte, no que tange ao encarceramento, os distritos policiais e cadeiões não são, sob quaisquer argumentos, instituições destinadas ao cumprimento da pena privativa de liberdade. Há uma completa ausência de pessoal técnico minimamente especializado no tratamento do recluso, conforme determina a Lei de Execução Penal, em sintonia com o que apregoam os tratados e convenções internacionais, aos quais o Brasil acatou, incorporando-os à Constituição Federal e aos Programas Nacional e Estadual de Direitos Humanos. E, principalmente, não só punir o crime mas recuperar os criminosos, é o que caracteriza a pena privativa de liberdade (Foucault, 1986).

Concebidos para reabilitar os indivíduos punidos são os estabelecimentos submetidos à Secretaria de Estado da Administração Penitenciária. São Paulo é o único estado da Federação que possui em sua estrutura de governo uma pasta exclusiva para a gestão penitenciária. Nos demais, as unidades para cumprimento da pena privativa de liberdade estão submetidas às secretariais de justiça ou de segurança pública. Esta estrutura foi criada em 1994 após a execução de 111 presos no complexo do Carandiru pela Polícia Militar durante um motim, como resposta às pressões de organismos nacionais e internacionais vinculados à proteção dos direitos humanos.

A administração penitenciária em São Paulo é dividida em três órgãos, com competências executivas: a) Coordenadoria dos Estabelecimentos Penitenciários - Coespe, aporte executivo da Secretaria, incumbe-se da implementação das diretrizes político-institucionais nas unidades; é de sua responsabilidade a estrutura e manutenção física dos estabelecimentos, a segurança e disciplina, a movimentação de presos entre as unidades, seja respeitando a progressão de regime prevista em lei ou por medida de segurança; as áreas de saúde, reabilitação e produção; b) a Escola da Administração Penitenciária, cuja atribuição é a capacitação de todo quadro funcional e dirigente das unidades prisionais; c) a Fundação Professor Doutor Manoel Pedro Pimentel - Funap, com a atribuição de proporcionar trabalho, formação profissional, educação e cultura para os prisioneiros do Estado.

Afora os arranjos formais de seus organogramas, uma característica indelével da organização penitenciária, conforme citado anteriormente, é o embate diuturno entre suas finalidades de punir e reabilitar. Esse embate é parte fundamental na composição penitenciária, no seu cotidiano, nos seus procedimentos mais corriqueiros, na proposição de atividades, na sua rotina, na relação institucional entre diretorias, seções e departamentos, na avaliação da sua gestão, nas reformas físico-estruturais e mesmo na formulação de sua arquitetura, nos seus regulamentos, na nomeação e atribuição de cargos e funções. 
Emerge desse embate a função de punir, consolidando os desígnios que Ihe são pertinentes. Dessa forma, o controle da massa encarcerada e a subjugação dos indivíduos punidos ao sistema social do cárcere, às suas normas e valores, convertem-se na finalidade da organização penitenciária. Essa perspectiva materializa-se no cotidiano prisional mediante relações pactuadas entre os corpos funcional e dirigente das unidades prisionais e lideranças da população carcerária. É um terreno pantanoso que proporciona um equilíbrio tênue e sensível, obtido mediante negociações ininterruptas entre estes segmentos, entre as quais inclui-se a distribuição de castigos, posições e privilégios (Coelho, 1987).

Essa nítida primazia da gestão penitenciária prescreve de forma inequívoca os programas e atividades identificados com a reabilitação dos prisioneiros, que passam a pautar sua organização e funcionamento pelos fundamentos da contenção, da vigilância, da subjugação dos indivíduos ao cárcere.

\section{Educação de adultos presos}

Presente desde os primórdios da prisão, a educação é arrolada como atividade que visa a proporcionar a reabilitação dos indivíduos punidos. Contudo, considerando que os programas da operação penitenciária apresentam-se de forma premente a fim de adaptar os indivíduos às normas, procedimentos e valores do cárcere - afiançando, portanto, aquilo que se tornou o fim precípuo da organização penitenciária: a manutenção da ordem interna e o controle da massa carcerária - quais são as possibilidades para uma "educação autêntica, que não descuide da vocação ontológica do homem, a de ser sujeito" (Freire, 1979, p. 66)?

No interior das prisões, as contradições do processo de ajustamento materializam-se nas possibilidades concretas dos indivíduos punidos preservarem-se como sujeitos; na resistência a subjugarem-se plenamente aos valores da instituição e do sistema social que the é inerente.

A resistência prisioneira ao controle carcerário (...) é muito mais forte e presente que seu raro registro na literatura faz supor (...). As pessoas presas conseguem manter a identidade, os valores de origem e grupais, a perspectiva de vida e de liberdade, a despeito das longas condenações e de todos os fortes e rigorosos meios de controle e sujeição utilizados pela instituição penitenciária. (Rocha, 1994, p. 3)

A educação formal não permanece, em absoluto, neutra nesse processo pleno de contradições de subjugação e resistência. "A característica fundamental da pedagogia do educador em presídios é a contradição, é saber lidar com conflitos, saber trabalhar as contradições à exaustão" (Gadotti, 1993, p. 143).

Por um lado, as rígidas normas e procedimentos oriundos da necessidade de segurança, ordem interna e disciplina das unidades que prescrevem as atividades escolares, a vigilância constante ou até mesmo a ingenuidade dos educadores, podem contribuir para que a escola seja mais um dos instrumentos de dominação, subjugando os indivíduos punidos ao "sistema social da prisão" (Sykes, 1999, p. 9) e ao "mundo do crime" (Ramalho, 1979, p. 163). Por outro lado, a escola pode apresentar-se como um espaço que se paute por desenvolver uma série de potencialidades humanas, tais como: a autonomia, a crítica, a criatividade, a reflexão, a sensibilidade, a participação, o diálogo, o estabelecimento de vínculos afetivos, a troca de experiências, a pesquisa, o respeito e a tolerância, absolutamente compatíveis com a educação escolar, especificamente a destinada aos jovens e adultos.

Nos estabelecimentos penais, a educação compõe a área de reabilitação, sendo a ela subordinada hierarquicamente. A manutenção de suas atividades, contudo, em todo 0 
tempo, observou a participação de outras instituições não pertencentes propriamente à unidade prisional. Sua organização e funcionamento são decorrentes, dessa forma, das normas e diretrizes das instituições que as coordenaram, ao longo dos anos.

Até o final da década de 1970, as escolas no interior das unidades prisionais regulavam-se observando a organização da rede regular de ensino estadual. 0 calendário escolar, o material didático, os processos de avaliação e promoção de séries eram análogos aos do ensino destinado às crianças.

A inadequação dessa proposta é patente. 0 primeiro aspecto reside na renúncia em inserir os encarcerados na educação destinada aos adultos, corporificada no cenário educacional brasileiro desde a década de 1930. Um segundo aspecto a acometer a qualidade desse ensino relaciona-se à extrema rotatividade da população carcerária entre as unidades do sistema penal. Um ensino de oito séries anuais, afora a possibilidade de repetência dos alunos, praticamente inviabiliza a conclusão dessa fase escolar pelos encarcerados.

Em 1979 cessaram as atribuições da Secretaria de Estado da Educação de manuten ção da escola nas prisões. Tal interrupção ocasionou uma lacuna na realização dessas atividades, culminando na mobilização e aglutinação de instituições estranhas à educação escolar propriamente, que condensaram uma série de ações para viabilizá-las.

Proeminente, nesse sentido, foi a iniciativa da Funap, órgão da própria Administração Penitenciária, em firmar convênio com duas instituições responsáveis pela educação de jovens e adultos: a Fundação Mobral - Movimento Brasileiro de Alfabetização - e a Fundação Roberto Marinho. Além de passar a desempenhar um papel importante na organização das atividades escolares, a Funap possibilitou que 0 ensino nas prisões ocupasse um lugar próprio no cenário educacional brasileiro de jovens e adultos.
Sua organização ef etivou-se observando as diretrizes programáticas da Fundação Mobral, posteriormente Fundação Educar, no que respeita ao ensino de 1 à à 4 a série. Denominado Programa de Educação Básica (PEB), foi subdividido em três etapas, PEB I, PEB II e PEB III, caracterizando, no sistema penal, o Nível I. Para 0 ensino de 5a à 8 a série - 0 Nível II - conforme diretrizes da Fundação Roberto Marinho, que pressupõem a organização de grupo de alunos por disciplinas: Língua Portuguesa, Matemática, História, Geografia e Ciências, e o exercício da pluridocência.

0 calendário letivo em todas as escolas do sistema penal paulista é organizado de fevereiro a julho. Após um recesso de quinze dias, o reinicio ocorre em agosto, estendendo-se até meados de dezembro. Entretanto, os motivos para o cancelamento das aulas não são poucos, mormente por questões relativas à segurança e disciplina.

Rotina da segurança em todas as unidades do sistema são as blitz. Caracterizam-se por revistas em todas as celas, normalmente planejadas em sigilo pela área de segurança, possuindo a prerrogativa de ser inesperada. Não existem períodos sistemáticos para sua realização, que varia segundo ocorrências no estabelecimento. Esse desígnio paralisa todas as atividades da unidade, pois os presos devem permanecer trancados nas celas para que se cumpra a revista.

Por vezes, a falta de agentes penitenciários também impede o funcionamento da escola. Os alunos presos são revistados quando saem do pátio para a escola e quando retornam. A falta de funcionários em determinados dias e horários impede a realização desse procedimento, impedindo a locomoção dos presos na unidade.

$\mathrm{Na}$ grande maioria dos estabelecimentos penais, a escola é 0 único local onde toda a população carcerária se encontra. No cotidiano permanecem separados nos raios onde estão dispostas suas celas. São comuns boatos de que 
algum "acerto de contas" (o termo enseja o uso da violência) entre os presos será efetuado na escola, oportunidade única para encontrar pessoas que estão em outros raios. Esse fato igualmente acarreta a interrupção das atividades.

Quando surgem ocorrências concretas na escola, tais como a descoberta de um túnel para fuga ou esconderijo de armas, as atividades escolares são suspensas por um período muito maior se comparado ao mesmo acontecimento em outro local da prisão 0 motivo alegado pelo corpo dirigente é o de que não se pode proibir o uso do pátio ou da cozinha, por exemplo, sem o risco de movimentos de motins ou rebeliões. No caso da escola, seu fechamento não traz conseqüências mais graves à ordem interna das prisões - prioridade da organização.

Afora os motivos de segurança, as aulas são paralisadas, inexoravelmente, uma vez por mês, no dia denominado como pecúlio. À população carcerária não é permitido manuseio de dinheiro. Aqueles que exercem alguma atividade remunerada, apresentam uma lista de compras a ser efetuada pela penitenciária (Setor de Pecúlio), que repassa aos presos os produtos. Nesse dia, a escola permanece sem atividades.

A carga horária diária das aulas é de duas horas para cada turma, de segunda a sexta-feira. A diretriz, no que respeita ao número de alunos, preconiza que sejam matriculados vinte para cada classe de PEB I e vinte e cinco para cada um das demais fases do ensino fundamental.

É bastante comum, contudo, os diretores de educação das unidades excederem esse número. Ocorre uma quantidade razoável de faltas, principalmente nos locais em que a freqüência não é obrigatória. As justificativas para as ausências incidem: a) nos atendimentos de ordem jurídica, médica ou social; b) no trabalho, pois apesar de os alunos serem dispensados para as aulas, em momentos de picos de produção não há essa concessão, ocorrendo então a opção pelas oficinas que, além da remuneração, possibilita a remição de pena, na proporção de três dias trabalhados, um a menos na sentença; c) na opção do aluno em não ir à aula em determinado dia; d) na concorrência da escola com outras atividades da unidade, principalmente as esportivas. 0 registro de ausências é maior quando são realizados campeonatos. Normalmente, sobre esses campeonatos, incide uma rede de apostas dos encarcerados, daí então 0 grande interesse em acompanhá-lo.

Em determinados estabelecimentos penais existe a obrigatoriedade da freqüência à escola. Tal fato configura-se contrário à proposta de reabilitação penitenciária visto que 0 êxito dessa terapêutica penal funda-se na participação voluntária do apenado nos programas (Rodrigues, 1999). Ao pessoal penitenciário incumbe-se a motivação para tanto.

Concernente á obrigatoriedade da educação, contudo, a grande maioria das unidades prisionais adota um procedimento que consiste em não impor tal condição num primeiro momento. Porém, uma vez matriculado, 0 aluno não pode ausentar-se sem justificativa. Caso não possua o ensino fundamental completo e, mesmo assim não queira estudar, deve assinar um "termo de responsabilidade" que será anexado ao seu prontuário, o qual, concretamente, transfigura-se na imposição, observando-se 0 receio dos encarcerados em assumir formalmente não tencionar matricular-se na escola, pois que há um temor que a Comissão Técnica de Classificação, conforme veremos adiante, ao avaliar sua solicitação de benefício, leve em conta esse fato, negando-Ihe a concessão.

Não obstante as dificuldades para 0 funcionamento regular da escola, observando-se os procedimentos da gestão penitenciária, um aspecto relativo à qualidade do ensino destinado aos homens e mulheres presos se sobressai. Trata-se da constituição da proposta de ensino supletivo no sistema penal paulista, a qual ensejou a possibilidade de ingresso do aluno encarcerado na escola a qualquer tempo, sem observar nenhum 
período preestabelecido, atentando-se para a especificidade da organização penal.

Sua inclusão efetiva-se após diagnóstico do seu desenvolvimento e aprendizagem escolares, realizados pelos pró prios educadores. Denominado Processo de Triagem, constitui-se de três etapas, a saber: prova escrita de Língua Portuguesa e Matemática, entrevista e adaptação em sala de aula.

Esse processo de triagem deve ser realizado apenas na primeira vez em que 0 aluno se matricula no programa de educação da Funap. A partir de então, os dados relativos ao seu grau de aprendizado e respectiva etapa que está cursando, seriam registrados no documento individual do aluno, denominado Histórico Escolar, o qual é atualizado com as informações pertinentes ao seu desenvolvimento escolar. Esse documento acompanha o aluno na movimentação pelas unidades do sistema penitenciário, de forma a permitir sua reinserção na escola.

A estrutura do programa de educação: Nível I - PEB I, II e III - correspondente ao ensino de 1 à à 4á série; e Nível II, de 5 a à 8aㅡ série, conforme já citado, permaneceu no sistema penal do estado de São Paulo, mesmo após a extinção da Fundação Educar, em 1990. A certificação, até então realizada por aquela Fundação, passou a ser constituída como uma "Declaração de Conclusão" fornecida pela Funap, sem o reconhecimento do Ministério da Educação ou do Conselho Estadual de Educação. Essa Declaração possui um valor maior no interior das unidades prisionais. Anexada ao prontuário dos alunos, tem a finalidade de atribuir boa conduta carcerária ao seu portador, quando for organizar a solicitação dos benefícios previstos em lei, principalmente a progressão de regime, cujo parecer final cabe à Comissão Técnica de Classificação.

Tal modalidade de ensino, caracterizada como de suplência, não prevê a retenção do aluno em qualquer de suas etapas. A avaliação é realizada de forma contínua e, ao atingir os objetivos mínimos previstos para cada uma das fases, o aluno é promovido à fase seguinte. Esse critério encerra, ainda, a promoção do Nível I para o Nível II.

No que tange à conclusão do Nível II, 0 ensino fundamental, a avaliação é realizada por professores e instituições alheios ao processo de ensino e aprendizagem propriamente. Trata-se do Centro de Exames Supletivos (Cesu), órgão da Secretaria de Estado da Educação, responsável pela realização dos Exames Oficiais de Suplência em todo o estado de São Paulo.

As provas do Cesu, como são conhecidas nas escolas das prisões, são realizadas uma ou duas vezes por ano, sendo estendida aos alunos encarcerados. São organizadas por disciplina e um conceito igual ou superior a cinco, habilita o aluno-candidato a receber um atestado de aprovação naquela disciplina. 0 certificado de conclusão do ensino fundamental é obtido após a aprovação nas cinco disciplinas que compõem o currículo, atualmente: Língua Portuguesa, História, Geografia, Ciências e Matemática. Essa forma de avaliação dos alunos para certificação na educação fundamental encerra um paradoxo. Durante o percurso de ensino e aprendizagem, os processos de avaliação são contínuos, participativos e qualitativos. Ao final do percurso, para obter a certificação, 0 aluno é submetido a uma série de testes objetivos, identificados com conteúdos programáticos (Secretaria de Educação - Centro de Exames Supletivos, 1989) diversos daqueles constituintes dos materiais didáticos dos alunos.

A estrutura e o funcionamento do programa de educação de adultos presos sofreram alterações, a partir de 1997, decorrentes da implementação do Telecurso 2000.

O Programa de Educação Básica - PEB, com três etapas, passou a ser denominado Programa de Alfabetização, subdividido em apenas duas: Alfabetização I e Alfabetização II (ALFA I e II). A fase subseqüente da educação fundamental constituiu o Telecurso 2000, 
correspondente ao programa de ensino de $3^{3}$ à $8^{\underline{a}}$ série, e organizada segundo a divisão das disciplinas que compõem o currículo: Língua Portuguesa, Matemática, História, Geografia e Ciências.

A proposta curricular para alfabetização foi igualmente alterada. Os objetivos e conteúdos pertinentes a essa fase escolar foram extraídos e readequados da Proposta Curricular para o 1 은 Segmento do Ensino Fundamental de J ovens e Adultos (São Paulo: Ação Educativa; Brasília: MEC, 1997), elaborada pela organização não-governamental Ação Educativa, a partir de um amplo e democrático processo, que contou com a participação de organizações educacionais públicas e da sociedade civil, vinculadas à Educação de J ovens e Adultos, com o apoio da Secretaria de Educação Fundamental do MEC. A Funap esteve presente nesse percurso. Ao final do processo, o MEC manifestou interesse em co-editar e distribuir os resultados dos trabalhos, constituindo uma proposta curricular basilar à elaboração de projetos voltados para educação de jovens e adultos no âmbito nacional. (São Paulo: Ação Educativa; Brasília: MEC, 1997, p. 5).

Fundamenta essa proposta curricular a intenção de concorrer para a estruturação e organização de programas de educação destinados aos jovens e adultos " 0 objetivo deste trabalho é oferecer um subsídio que oriente a elaboração de programas de educação de jovens e adultos e, conseqüentemente, também o provimento de materiais didáticos e a formação de educadores a ela dedicados" (São Paulo: Ação Educativa; Brasília: MEC, 1997, p. 13).

A partir dessa orientação e com o propósito de manter a educação dos encarcerados inserida no cenário educacional brasileiro de jovens e adultos, a Funap desencadeou um processo, envolvendo coordenação e educadores, para a reorganização curricular destinada ao primeiro segmento do ensino fundamental (Funap, 1997). Foram seis meses para construção e implementação do projeto, caracterizado como piloto, a partir do qual foram constituídas as bases para sua difusão às demais unidades do sistema penal paulista, o que veio a ocorrer somente em 2001, devido à falta de recursos financeiros.

Desde 1987 a educação no sistema penitenciário paulista é incumbência da Funap. Atualmente, contudo, uma variada gama de parcerias foram arroladas no sentido de possibilitar a organização e funcionamento das escolas nas prisões (Quadro 1). São $11 \mathrm{mil}$ alunos matriculados em 62 unidades prisionais do Estado.

Um aspecto não propriamente didático-pedagógico, relacionado à organização e ao funcionamento das escolas, requer relevância, pois sua interferência é decisiva qualitativamente para o programa de educação de adultos presos.

No interior das unidades prisionais, a educação é subordinada à área de reabilitação. Seu corpo técnico é o responsável pela realização dos exames criminológicos e emissão do parecer acerca da concessão dos benefícios solicitados pelos indivíduos presos.

Para essa concessão, conforme já mencionado, incide uma primazia em avaliar a adaptação do indivíduo punido ao sistema social da prisão, a partir da qual infere-se sobre sua reabilitação. Dessa forma, decorre que os encarcerados passam a organizar sua vida prisional e pautar sua conduta de forma a apresentar-se com um "bom preso" pois, do contrário, os benefícios Ihes serão negados.

Esse proceder, invariavelmente, prejudica as atividades educativas, principalmente devido ao fato de que o setor de educação deve enviar à Comissão Técnica de Classificação um relatório sobre a conduta do aluno.

0 processo educativo requer a participação ativa dos educandos nas aulas, numa série de "erros" e "acertos" que se constituem como parte do processo de aprendizagem. A necessidade de mostrar-se como um "bom preso" ao professor, com a intenção sub-reptícia de obter uma concessão, pode 
Quadro 1. Instituições que atuam no Programa de Educação de Adultos

Presos do estado de São Paulo e composição do quadro docente.

\begin{tabular}{|l|c|}
\hline \multicolumn{1}{|c|}{ Instituições } & Número de docentes \\
\hline $\begin{array}{l}\text { Funap } \\
\text { - Monitores concursados }\end{array}$ & 244 \\
- Monitores presos & 104 \\
- Monitores estagiários & 100 \\
\hline Coespe - Funcionários das unidades prisionais em desvio de função & 08 \\
\hline Secretaria de Estado da Educação - Professores comissionados & 06 \\
\hline $\begin{array}{l}\text { Secretaria de Estado de Educação - Professores que assumiram a docência nas uni- } \\
\text { dades prisionais na atribuição de aulas }\end{array}$ & 36 \\
\hline $\begin{array}{l}\text { Secretarias Municipais de Educação - Professores que assumiram a docência nas uni- } \\
\text { dades prisionais na atribuição de aulas }\end{array}$ & 10 \\
\hline Senai - Professores cedidos através de parceria com Funap & 10 \\
\hline Fumec - Fundação Municipal para Educação Comunitária - Campinas & 18 \\
\hline TOTAL & 332 \\
\hline
\end{tabular}

inviabilizar o processo educativo, mormente organizado tendo em vista o desenvolvimento de uma série de potencialidades dos alunos.

Observando-se que "fica difícil desenvolver efetivamente o programa de educação ou de trabalho, se eles estiverem ligados ao esquema de funcionamento da prisão" (Salla, 1993, p. 95), a participação do corpo docente nos exames e na elaboração dos pareceres percorre uma direção contrária: transportar para o espaço da sala de aula os procedimentos pertinentes à gestão penitenciária, suas normas, procedimentos e valores. Não obstante, o programa de educação de adultos presos apresenta-se com os objetivos de: a) "criar condições para 0 desenvolvimento e aprendizagem dos alunos de forma participativa e crítica"; b) "desenvolver as potencialidades dos alunos, preparando-os para o exercício pleno da cidadania"; c) "estimular e conscientizar os alunos para a importância dos estudos, buscando alternativas atrativas para a participação" (Rusche, 1995, p. 28), dos alunos em sala de aula na avaliação de sua conduta carcerária, torna-se aspecto acometedor para a consecução destas finalidades educativas.

0 percurso que consolidou a organização e funcionamento das escolas no interior dos estabelecimentos penais evidencia, portanto, uma condensação de variados procedimentos pertinentes, de um lado, à gestão penitenciária e, de outro, ao fazer pedagógico propriamente.

0 primeiro fato que poderíamos citar acerca da especificidade da Educação de Adultos Presos é 0 de que ela faz parte, enquanto processo metodológico, da História da Educação de Adultos e tem, portanto, seu desenvolvimento pedagógico inserido nessa história. 0 segundo fato é o de ser um projeto de educação que se desenvolve no interior das prisões e que, dessa forma, está inserido também na história das prisões e das formas de punição. (Rusche, 1997, p. 13)

Normas, valores e padrões identificados com estes dois aspectos, que perpassam a 
organização das atividades escolares destinadas aos encarcerados, raramente são passíveis de coadjuvarem-se. É no embate diuturno entre pressupostos e finalidades diferentes, até opostas, que emergem a organização e o funcionamento das escolas no sistema penal paulista.

As possibilidades e as contradições de uma "educação autêntica, que não descuide da vocação ontológica do homem, a de ser sujeito" (Freire, 1979, p. 66) configuram-se de forma preponderante nos aspectos metodológicos.

No interior das prisões, a metodologia é o fator diferencial do trabalho educativo, na medida em que possibilita, por um lado, o engajamento da educação aos procedimentos da gestão carcerária, pautados pelo princípio da punição e de manutenção da ordem interna das prisões. Por outro, permite a constituição desse trabalho, enquanto uma das possibilidades concretas para a preservação dos indivíduos punidos à subjugação carcerária.

As possibilidades da metodologia em desvincular as atividades educativas do esquema disciplinar das prisões materializam-se na prática de sala de aula: nas relações estabelecidas entre os alunos e destes com os educadores, na participação individual e em grupo nos trabaIhos, no debate, nos questionamentos, na reflexão, no respeito, na tolerância, no diálogo e nos conteúdos. A observação desses aspectos pode contribuir para a constituição do espaço escolar, diferenciando-o da técnica penitenciária.

Nos interstícios das contradições, presentes e inerentes a todos os processos de dominação e subjugação, arrogam-se as possibilidades concretas para a constituição da escola, como espaço diferenciado da técnica penitenciária. 0 confronto direto ou a mera sublevação ante os procedimentos da gestão carcerária fatalmente acarretam a própria afirmação destes. Observando-se a nítida prioridade de manutenção da ordem interna das prisões, no cotejo avultam-se os preceitos relativos aos esquemas disciplinares e punitivos, solidificando-os na organização.
A proposta de reabilitação penitenciária: o dilema punir/educar

Desde que a prisão tornou-se a pena por excelência, relegando os castigos corporais, os suplícios físicos, desonras, banimentos, esforços extenuantes, etc. (Rocha, 1994), recaiu sobre ela a dupla função de punir e reabilitar.

Fundada nesta dupla finalidade a pena de encarceramento se sedimentou e se proliferou desde os primórdios do século XIX, inicialmente na Europa e, posteriormente, para 0 restante do mundo.

Considerando a tarefa de reabilitar os indivíduos punidos, áreas diversificadas do conhecimento foram aglutinadas na instituição carcerária para consecução dessa finalidade: arquitetura, sociologia, psiquiatria, serviço social, psicologia, pedagogia e direito.

A reabilitação dos indivíduos por meio do encarceramento, fruto da aglutinação desses saberes, funda-se em três grandes princípios: 0 isolamento, o trabalho penitenciário e a modulação da pena (Foucault, 1986). A partir deles tornou-se possível a edificação de um saber técnico-científico sobre os indivíduos, declinando o foco de ação do crime, para aquele que o cometeu. 0 indivíduo é o foco central da operação penitenciária, não o seu ato.

0 princípio do isolamento efetiva-se, primeiro, em relação ao indivíduo transgressor com o mundo exterior. Depois, mediante a classificação dos detentos, um em relação aos outros, dispostos a partir da função de individualização da pena. Essa função é desencadeada tendo em vista o indivíduo punido (não o infrator), objeto de transformação do aparelho carcerário.

J unto ao isolamento, o trabalho é definido como parte constituinte da ação carcerária de transformação dos indivíduos. Impõe-se, não como atividade de produção, mas pelos efeitos que faz desencadear na 
mecânica humana, proporcionando a ordem e a regularidade; o que

sujeita os corpos a movimentos regulares, exclui a agitação e a distração, impõe uma hierarquia e uma vigilância que serão ainda mais bem aceitas, e penetrarão ainda mais profundamente no comportamento dos condenados. (Foucault, 1986, p. 203)

Por fim, o princípio da autonomia penitenciária que permite a modulação da pena, ajustando-a àquela transformação, uma vez que a duração do castigo não deve relacionar-se diretamente à infração, mas sim à transformação útil do indivíduo, no decorrer do cumprimento da sentença. A operação penitenciária é quem deve controlar os efeitos da punição.

A fim de processar a transformação útil do indivíduo, a prisão deve, simultaneamente, ser o local de execução da pena e de uma sistemática e rigorosa observação dos indivíduos punidos. É a partir desta que os rigores, atenuantes, progressões e regressões da pena serão aplicados.

Tais princípios, desde o surgimento da pena de encarceramento, formaram os fundamentos a partir dos quais foram edificadas as máximas para uma adequada administração penitenciária, ou seja, que lhe proporcionariam a consecução das finalidades de punir e reabilitar o indivíduo transgressor. "Princípios de que, ainda hoje, se esperam ef eitos tão maravilhosos, são conhecidos: constituem há 150 anos as sete máximas universais da boa 'condição penitenciária'" (Foucault, 1986, p. 221). São elas: 1a) Correção - a prisão deve ter como função essencial a transformação do comportamento do indivíduo; a recuperação e reclassificação social do condenado;

2a) Classificação - o indivíduo condenado deve ser isolado, primeiro em relação à sociedade, depois repartidos entre eles, a partir de critérios que envolvam idade, sexo, disposições e técni- cas que se pretendam utilizar para que se processe sua transformação, bem como suas respectivas fases para operá-las; a pena deve ser não só individual, como individualizante; 3a) Modulação das penas - a pena deve ser proporcional, de acordo com a individualidade dos condenados e com os resultados da terapêutica penal, com vistas a se processar sua transformação, prevendo progressos e recaídas inerentes deste processo;

4a) Trabalho como obrigação e como di reito é considerado como uma das peças fundamentais para transformação e socialização dos detentos, que devem aprender e praticar um ofício, provendo com recursos a si e à sua família;

5ạ) Educação penitenciária - deve ser preocupação diuturna do poder público dotar 0 indivíduo da educação, no interesse da sociedade, provendo sua instrução geral e profissional;

6â) Controle técnico da detenção - a gestão das prisões, seu regime, deve ser realizado por pessoal capacitado, que zele pela boa formação dos condenados;

7â) Instituições anexas - o indivíduo deve ser acompanhado por medidas de controle e assistência, até que se processe sua readaptação definitiva na sociedade.

A partir de tais pressupostos, combinando seus efeitos punitivos à operação correcional, a prisão apresenta-se como a instituição de combate ao crime. A constatação de que ela não reduz a criminalidade é tão antiga quanto a própria prisão. Exceto pelos números, as críticas ao seu fracasso permanecem idênticas nos mais de cento e cinqüenta anos de sua existência. Antes de contribuir para a extinção do comportamento criminoso, a prisão produz a reincidência. Afinal, a prisão propicia a organização dos delinqüentes, na medida em que desencadeia uma forma de socialização em seu submundo, estabelecendo solidariedade, cumplicidade e hierarquia entre eles. 
De forma bastante singular, entretanto, a prisão, invariavelmente apresenta-se como a solução para o problema da criminalidade que ela própria contribui para sedimentar. Sempre acompanhada de planos de reformas, os quais, em seu bojo, reafirmam as máximas que constituíram a prisão desde seu surgimento.

0 que justifica a existência capilar da prisão na sociedade, não obstante seu absoluto fracasso em combater a criminalidade, antes que suprimir as infrações, é distingui-las, distribuí-las e até utilizá-las:

Organizar as transgressõ es numa tática geral de sujeições (...) É uma maneira de gerir as ilegalidades, de riscar limites de tolerância, dar terreno a alguns, de fazer pressão sobre outros, de excluir uma parte, de tornar útil outra, de neutralizar estes, de tirar proveito daqueles. (Foucault, 1986, p. 226)

A operação penitenciária, portanto, gerencia a delinqüência, inserida numa estratégia global de dominação e disciplinarização - "Corrigir as pessoas sempre foi um objetivo estreitamente ligado ao uso que se quer fazer delas" (Rocha, 1994, p. 170).

Aspecto central nessa operação é a construção da delinqüência que ela faz desencadear nos indivíduos punidos. 0 condenado - infrator na justiça penal - torna-se o objeto de saber da técnica penitenciária que, em seu lugar, coloca um outro personagem: 0 delinqüente. 0 infrator se constitui por um ato (transgressor), o delinqüente se refere a toda uma vida do indivíduo, objeto de conhecimento da técnica punitiva:

\footnotetext{
A diferença entre um infrator e um delinqüente está em que o que caracteriza o delinqüente não é 0 ato da infração, mas a sua vida. A justiça condena o infrator pelo ato da infração, o sistema carcerário não apenas faz com que a infração o marque pela vida toda, como realiza a socialização que 0 insere definitivamente no mundo do crime. (Ramalho, 1979, p. 163)
}

A lenta formação do delinqüente transparece na investigação biográfica, fator de extrema importância na história da penalidade, "porque faz existir o criminoso antes do crime" (Foucault, 1986, p. 211). A biografia marca o autor da transgressão com uma criminalidade que, portanto, exige as medidas da ação penitenciária. Nesse aspecto, confundem-se os discursos penal e psiquiátrico. No ponto de intersecção desses discursos, surge a noção de indivíduo perigoso, "que permite estabelecer uma rede de causalidade na escala de sua biografia inteira e um veredicto de punição - correção" (Foucault, 1986, p. 211).

Afora a perda da liberdade física (ou do direito de ir e vir), a prisão subjuga o detento ao comando de uma estrutura autoritária e de uma rígida rotina autocrática que opera como uma grande máquina impessoal. 0 controle sobre os indivíduos é exercido de forma ininterrupta, regulando-se de modo minucioso todos os momentos de sua vida. Com a nítida orientação de preservar a ordem, a disciplina, evitar fugas e motins, a organização penitenciária elege como forma eficaz submeter o recluso, cercear quaisquer possibilidades do exercício de sua autonomia (Thompson, 1976).

Ao adaptar sua conduta e comportamento às normas e padrões da instituição, o preso gradualmente passa a obter acesso a determinados bens ou prerrogativas na prisão. Certas necessidades, procedimentos ou vontades que na vida fora da prisão eram absolutamente corriqueiras, no interior dela adquirem a qualidade de privilégios: tomar um café quente, ir a algum lugar sem motivo aparente, faltar ao trabalho ou à aula, sair com um grupo ou outro de pessoas, dormir ou acordar em horários diferentes, etc.

Em contrapartida, essa adaptação tende à despersonalização do sujeito apenado - a mortificação de seu eu (Goffman, 1996). Quanto maior a intensidade do ajustamento ao sistema social da prisão, maiores as 
possibilidades de se alcançar os privilégios de que ela dispõe. Ao contrário, mostrar-se resistente acarreta ao indivíduo punido um maior rigor, severidade e endurecimento de seu regime.

No que concerne à administração penitenciária, o sistema de privilégios é vital para sua gestão, constituindo-se num dos sustentáculos de seu modelo organizacional. Em face da importância que esse sistema representa aos reclusos, inexoravelmente, ele se encerra como uma forma eficaz de controle da massa encarcerada. Comportamentos e condutas não desejáveis pela organização significam o impedimento em obtê-los. Tal controle tende a intensificar-se, pois, no interior das prisões, todas as esferas da vida do indivíduo interpenetram-se. Assim, ser recriminado ou avaliado negativamente em determinada atividade influencia e repercute nas demais, sendo toda sua conduta considerada como não adequada.

É a partir desse pressuposto que o indivíduo passa a organizar toda sua vida encarcerada. Mais que uma motivação, torna-se uma obsessão, que se materializa na inserção em atividades que permitem a remição de pena trabalho penitenciário - ou nos programas que Ihe atribuem a qualidade de uma boa conduta caso da educação e cursos em geral, cultura, esportes e grupos terapêuticos. Manifesta-se também na sua forma de proceder e de relacionar-se com outros presos, funcionários, técnicos e dirigentes. "Se o preso demonstra um comportamento adequado aos padrões da prisão, automaticamente merece ser considerado como readaptado à vida livre" (Thompson, 1976, p. 42).

Nesse sentido, essa busca incessante de mostrar-se adequado aos padrões da prisão transforma-se em princípio e fim das ações dos encarcerados. Os objetivos que, pressupõe-se, deveriam ser inerentes às atividades, seja de educação, cultura, esportes, profissionalização ou terapêuticas, são declinados em favor dessa busca.
Indivíduo "reabilitado", portanto, seria o infrator plenamente ajustado ao aparelho carcerário; especificado e patologizado técnica e cientificamente em face da sociedade "preso um dia, preso toda a vida" (Castro et al., 1984, p. 110).

Se não, vejamos.

A avaliação acerca da reabilitação dos encarcerados no estado de São Paulo é realizada pela Comissão Técnica de Classificação (CTC), que funciona no interior das unidades prisionais. É presidida pelo diretor e deve ser composta, no mínimo, por dois chefes de serviço, um psiquiatra, um psicólogo e um assistente social. Seu resultado é denominado Exame de Personalidade e compõe o prontuário criminológico dos indivíduos punidos (Lei de Execução Penal, Artigo 7ํ).

Esse Exame configura-se como um inquérito sobre o indivíduo punido, e não sobre o transgressor, a fim de possibilitar a gestão da pena de encarceramento de forma individualizada. (Lei de Execução Penal, Art. 34 Exposi ção de M otivos). Não possui por finalidade a questão jurídica, a informação sobre a dinâmica do ato criminoso; não visa a elementos de prova ou instrutórios do processo:

Desloca-se a ênfase do ato para o comportamento individual. 0 que importa, sob essa perspectiva, é deslindar a pessoa do infrator, inquirir-lhe pensamentos inconfessáveis, desejos ocultos, tendências inconscientes com vistas a identificar-Ihe um potencial "criminógeo" que explique seu comportamento delinqüencial, caracterize sua responsabilidade criminal e justifique a aplicação da penalidade, via de regra privação da liberdade" (Adorno, 1991b, p. 66-67).

0 exame realizado pela CTC volta-se para a pessoa, sua realidade integral e individual, sua história de vida, em detrimento da conduta criminosa. Como já referido, o sujeito é o desígnio da ação carcerária, tornan- 
do-se objeto de saber da técnica penitenciária, que declina seu foco de ação do crime, para aquele que o cometeu:

Deve definir o perfil do preso, enquanto pessoa, que tem uma história de pessoa, que tem características, tendências, desejos, aptidões, interesses, aspirações de pessoa e que, como pessoa (e não só como criminoso), deve ser acompanhado e preparado para seu retorno ao convívio social. (Sá, 1996, p. 210)

Regime fechado, semi-aberto ou aberto, são as possibilidades para o cumprimento das penas privativas de liberdade no sistema progressivo, adotado pelo Brasil. A progressão, ou seja, a transferência para um regime menos rigoroso, é determinada pelo juiz, quando cumpridos ao menos um sexto da pena no regime anterior e pelo mérito do preso (resultado da CTC).

0 parecer da Comissão Técnica de Classificação deveria, assim, ser a avaliação de uma proposição de programas, com o acompanhamento sistemático de seus resultados em face dos indivíduos punidos. Em outros termos, uma avaliação longitudinal do indivíduo, de sua conduta e participação nas atividades. Na dinâmica penitenciária atual, contudo, o que se verifica é uma completa ausência desses procedimentos (Sá, 1996; Albergaria, 1990; Pitombo, 1985). Na verdade, sua realização efetiva-se tão somente mediante uma série de entrevistas, testes (psicológicos e psiquiátricos) e avaliações pontuais do encarcerado, realizadas por profissionais das áreas anteriormente referidas, cujo tempo médio de duração não ultrapassa uma hora.

0 corpo técnico das unidades prisionais dedica-se quase que exclusivamente à realização dos exames e do respectivo parecer dos indivíduos punidos, em detrimento da formulação, proposição e implementação de programas e atividades. Acentua-se, nesse sentido, a difusão dos aspectos de contenção e controle nos pareceres da Comissão Técnica de Classificação.
O parecer da CTC compõe o Prontuário Criminológico do prisioneiro subdividido em Dados de Observação Direta e Exames Técnicos. Os primeiros são relatórios relativamente padronizados, dos quais constam todos os aspectos da vida do indivíduo na prisão: trabaIho, escola, relação com familiares (quando das visitas nos finais de semana), participação nas atividades culturais, de lazer, esportivas e religiosas, relação com demais presos e com funcionários, apresentação pessoal, obediência ao regimento interno da unidade, cuidados com o patrimônio do Estado. Normalmente priorizam-se os aspectos disciplinares de sua conduta. São elaborados por cada um dos setores que organizam as respectivas atividades. Já os Exames Técnicos são compostos de: a) Estudo J urídico-penal; b) Estudo Social; c) Exame Psicológico; d) Exame Psiquiátrico. Esses exames efetivam-se mediante a realização de uma série de testes e entrevistas com os prisioneiros no momento mesmo da avaliação.

A partir destas informações, a Comissão delibera acerca da reabilitação dos prisioneiros. É patente uma certa hierarquia dos resultados obtidos por meio dos Exames Técnicos em relação aos Dados de Observação Direta. Caso as avaliações sejam dissonantes, normalmente há prevalência daqueles. Ao final do Prontuário Criminológico, um tópico denominado Conclusão traz uma síntese dos exames, encerrando com a deliberação acerca da reabilitação do indivíduo, os quais indicam nitidamente essa hierarquização.

Com a intenção de ilustrar esse fato, apresento os resultados referentes a dois prisioneiros, cujos pareceres foram desfavoráveis, conforme atestam seus prontuários criminológicos ${ }^{1}$.

1. Prisioneiros do Centro de Observação Criminológica - Complexo do Carandiru. Dados extraídos em outubro de 2000. 
Prisioneiro 1

Dados da Observação Direta

Relatório das áreas de segurança, disciplina e produção

- Sem registro de faltas disciplinares;

- Apresenta ótima conduta carcerária;

- Apresenta-se responsável para com o patrimônio da unidade;

- Apresenta-se respeitoso com os funcionários;

- Apresenta-se amistoso com os demais sentenciados;

- Apresenta-se amistoso, afetuoso e demonstra interesse pela família;

- Demonstra interesse e participa das atividades de lazer de forma disciplinada;

- Participa de atividade religiosa e demonstra fé;

- Apresenta aspecto pessoal cuidado, mostrando-se barbeado, asseado e penteado;

- Obedece passivamente ao regimento interno;

- Apresenta boa produtividade e bom desempenho no trabalho.

Relatório da área sociopedagógica

- Analfabeto quando entrou na prisão; não freqüentou escola porque morava e trabalhava na área rural;

- Na prisão conclui a disciplina de Língua Portuguesa, atualmente freqüenta o curso supletivo, equivalente da $5^{\mathrm{a}}$ a 8$^{\mathrm{a}}$ séries, nas disciplinas de Geografia, Ciências e Matemática;

- Interessado/ responsável;

- Participa das atividades de teatro e música, apresentando boa relação com o grupo/ utiliza-se da compreensão para aconselhar, pontuar e ajudar os integrantes/ engajado para preservar união e harmonia do grupo/ presença marcante e rica na constituição do grupo.

Conclusão da Comissão Técnica de

Classific ação acerca de sua reabilitação

- Apresenta instabilidade trabalhista / rigidez marcante / primitivismo / rude / necessidade de valorização pessoal / agressividade e impulsividades represadas graças a mecanismos externos / mecanismos frenadores repressivos e pouco confiáveis / autocrítica precária / movimentos internos com vista à regeneração não são satisfatórios;

- Parecer: Desfavorável.

Prisioneiro 2

Dados da Observação Direta

Relatório das áreas de segurança, disciplina e produção

- Sem registro de faltas disciplinares;

- Apresenta ótima conduta carcerária;

- Apresenta-se responsável para com o patrimônio da unidade;

- Apresenta-se respeitoso com os funcionários;

- Apresenta-se amistoso com os demais sentenciados;

- Apresenta-se amistoso, afetuoso e demonstra interesse pela família;

- Participa das atividades de lazer de forma disciplinada;

- Participa de atividade religiosa e demonstra fé;

- Apresenta-se aspecto pessoal cuidado, mostrando-se barbeado, asseado e penteado;

- Obedece passivamente ao regimento interno;

- Apresenta boa produtividade e bom desempenho no trabalho.

\section{Relatório da área sociopedagógica}

- Quando foi para a prisão estava matriculado na 7 a série do ensino fundamental;

- Na prisão, concluiu o ensino fundamental. Está cursando o ensino médio, do qual conclui Língua Portuguesa, História, Geografia e Matemática. Cursa atualmente Física e Biologia;

- Interessado/ responsável/ assíduo/ sua úni- 
ca dificuldade deve-se a problemas fonoaudiológicos;

- Participa das atividades de teatro e do curso de inglês, apresentando-se interessado/ responsável/ preocupado com a disciplina e comportamento;

- Atendimento psicológico individual por três vezes, apresentando reflexão sobre os assuntos abordados/ empenho/ procura simbolizar e significar seus atos.

Conclusão da Comissão Técnica de

Classific ação acerca de sua reabilitação

- Apresenta certa estabilidade trabalhista / contato pouco espontâneo / motivado por temores de desaprovação, crítica e recriminação / relata crimes buscando isenção da própria culpa e responsabilidade, denotando distanciamento afetivo marcante frente aos danos / busca de defesas para posicionar-se no meio de lidar com as demandas / rigidez / primitivismo / egocentrismo / avaliação superficiais e mobilizadas pelo próprio sofrimento / seus valores fogem do contexto social;

- Parecer: desfavorável.

Independentemente da situação concreta de existência dos indivíduos, de seu desenvolvimento e participação nos programas e atividades proporcionados pela unidade, os membros da CTC arrogam-se a prerrogativa de, no decurso de uma série de testes e entrevistas que não ultrapassam uma hora de duração, deliberar uma avaliação pertinente a toda uma vida, atribuindo aos indivíduos uma periculosidade latente e inscrita na escala de toda sua biografia, prolongando sua permanência no cárcere.

Os resultados desses dois prontuários demonstraram que as avaliações efetuadas pelas demais esferas da unidade prisional apontavam uma série de esforços dos indivíduos: bom desempenho e bons índices de produtividade no trabalho, participação e freqüência nas aulas, interesse para o aprendizado dos conteúdos programáticos da escola, integração com professores e demais alunos e compromisso com os estudos, entre outros. Esforços estes sumariamente ignorados pela Comissão, a qual possui a mais absoluta convicção em seus resultados e procedimentos criminológicos, cujos fundamentos produzem a anulação e mortificação dos sujeitos.

Dessa forma, os indivíduos cujas avaliações indicam assiduidade, participação, envolvimento e progressos, têm a solicitação de benefícios negada pela CTC e, ainda, vêem toIhidas suas possibilidades de ação no sentido de obtenção daquele benefício, uma vez que não são explicitados os motivos pelos quais não foram considerados reabilitados. E, quando expostos, o são de forma absolutamente sucinta e sem quaisquer orientações que possam reverter o parecer impingido. Evidencia-se justamente o contrário: a reabilitação requer a anulação do ser, não um empreendimento próprio para sua formação enquanto sujeito.

A contradição entre a educação e a reabilitação penitenciária incide preponderantemente nesse aspecto. A primeira almeja a formação dos sujeitos, a ampliação de sua leitura de mundo, o despertar da criatividade e da participação para a construção de conhecimentos, a transformação e a superação de sua condição. Já a segunda, atribui a absoluta primazia na anulação da pessoa, na sua mortificação enquanto sujeito, aceitando sua situação e condição como imutáveis ou, ao menos, cujas possibilidades para modificá-las estão fora de seu alcance.

\section{Referências bibliográficas}

ADORNO, Sérgio. A prisão sob a ótica de seus protagonistas. Itinerário de uma pesquisa. Tempo Social - Revista de Sociologia da USP, São Paulo, v. 3, n. 1 e 2, p. 7-40, 1991a. 
O Sistema Penitenciário no Brasil. Revista USP. São Paulo, março-abril-maio, 1991b.

ALbergariA, Jason. Pena privativa de liberdade. Rio Grande do Sul. Revista da Escola do Serviço Penitenciário do Rio Grande do Sul, Porto Alegre, ano 1, n.ำ 3, 1990.

BEISIEGEL, Celso de Rui. Estado e educação popular. São Paulo: Ática, 1984.

. Educação e sociedade no Brasil após 1930. In: História geral da civilização brasileira, São Paulo: Difel, 1982.

CASTRO, Myriam Mesquita Pugliese. Ciranda do medo - Controle e dominação no cotidiano da prisão. Revista USP, São Paulo, março-abril-maio, 1991.

CASTRO, Myriam Mesquita P., RESENDE, Regina Gattai de A., ABREU, Sérgio França A. e CHACON. Preso um dia, preso toda a vida: a condição de estigmatizado do egresso penitenciário. Temas IMESC; São Paulo, 1(2,) p. 101-117., 1984.

COELHO, Edmundo Campos. A Oficina do Diabo (Crise e conflitos no sistema penitenciário no Rio de J aneiro). Rio de J aneiro: Espaço e Tempo, luperj, 1987.

FISCHER, Rosa Maria. 0 Círculo do poder - as práticas invisíveis de sujeição nas organizações complexas. In: FLEURY, Maria Tereza Leme e FISCHER, Rosa Maria (org.). Cultura e Poder nas Organizações. 2ª ed. São Paulo: Atlas. 1996.

FISCHER, Rosa Maria e ADORNO, Sérgio. Análise do sistema penitenciário do estado de São Paulo: o gerenciamento da marginalidade social. São Paulo: Cedec, Relatório de Pesquisa, 1987 [mimeografado]. $19 \overline{8}$.

Políticas penitenciárias, um fracasso. Lua Nova - Cultura e Política, n.ำ34. São Paulo, abril - junho, p. 70-79,

FOUCAULT, Michel. Vigiar e punir: História da violência nas prisões. Trad. Lígia M. Pondé Vassallo. 4aa ed. Petrópolis: Vozes, 1986.

FREIRE, Paulo. Política e educação. 2ạ ed. São Paulo: Cortez, 1995.

Educação como prática de liberdade. Rio de J aneiro: Paz e Terra, 1983.

Pedagogia do oprimido, Rio de J aneiro: Paz e Terra, 1981.

Conscientização: teoria e prática da libertação. São Paulo: Ed. Moraes, 1980.

Educação e mudança. 18ª ed. Rio de J aneiro: Paz e Terra, 1979.

FUNAP.Presídios e Educação: Anais do I Encontro de Monitores de Alfabetização de Adultos Presos do Estado de São Paulo. São Paulo: Funap, 1993.

GADOTTI, M oacir. Educação como processo de reabilitação. In: MAIDA J .D. (org.). Presídios e educação. São Paulo: Funap, 1993.

GOFFMAN, Erving. Manicômios, prisões e conventos. Trad. Dante Moreira Leite. 5a ed. São Paulo: Perspectiva, 1996.

LEITE, J osé Ribeiro. Educação por trás das grades: Uma contribuição ao trabalho educativo, ao Preso e à Sociedade. Marília; 1997. Dissertação (Mestrado) - UNESP.

MIRABETE, J ulio Fabbrini. Execução penal: comentários à Lei no 7210, de 11-7-84. 8ạ ed. São Paulo: Atlas, 1997.

PITOM BO, Sérgio M. de Moraes. Ainda o exame criminológico. São Paulo, J ornal do Advogado, Ano XII, n.ำ122, 1985.

RAMALHO, J osé Ricardo. Mundo do crime: a ordem pelo avesso. Rio de J aneiro: Graal, 1979.

ROCHA, Luiz Carlos da. A Prisão dos pobres. São Paulo; 1994. Tese (Doutorado) - Instituto de Psicologia da Universidade de São Paulo. 
RODRIGUES, Anabela Miranda. A posição jurídica do recluso na execução da pena privativa de liberdade: seu fundamento e âmbito. São Paulo: IBCCrim, 1999.

RUSCHE, J esus Robson (org.) . Educação de adultos presos: uma proposta metodológica, São Paulo: Funap, 1995.

Teatro: gesto e atitude - Investigando processos educativos através de técnicas dramáticas, com um grupo de presidiários. São Paulo; 1997. Dissertação (Mestrado) - Instituto de Psicologia da Universidade de São Paulo.

SÁ, Alvino Augusto de. A recuperação dos sentenciados e a questão do exame criminológico "versus" parecer das comissões técnicas de classificação. Revista Brasileira de Ciência Criminais, São Paulo, , ano 4, n. 013 . Editora Revista dos Tribunais, 1996.

SALLA, Fernando Afonso). As prisões em São Paulo: 1822-1940. São Paulo: Annablume, 1999.

Educação como processo de reabilitação. In: MAIDAJ . D. (org. ), Presídios e educação. São Paulo, Funap, 1993.

SÃO PAULO: AÇÃO EDUCATIVA; BRASÍLIA: MEC Educação de J ovens e Adultos: Proposta curricular para 0 1ํo segmento do ensino fundamental. Ação Educativa: São Paulo; MEC: Brasília, 1997.

SYKES, Gresham M.,. The Society of Captives: a Study of a Maximum Prison. New J ersey: Princeton University Press, 1999.

THOMPSON, Augusto F. G. A Questão penitenciária. Petrópolis: Vozes, 1976.

Relatórios institucionais, regulamentações e leis

BRASIL. Programa Nacional de Direitos Humanos, 1996.

FUNAP. Quadro da composição docente no programa de educação de adultos Presos. São Paulo: FUNAP, 2001 [mimeografado].

. Quadro de estagiários. Gerência de recursos humanos, , São Paulo: Funap, 2000a [mimeografado].

. Projeto de ampliação do Telecurso 2000. Gerência de educação, cultura e lazer. São Paulo: Funap, 2000b [mimeografado].

. Plano de ação para 1999. Gerência de educação, cultura e lazer. São Paulo: Funap, 1999 [mimeografado].

Educação supletiva em estabelecimentos penitenciários do estado de São Paulo: um relato de experiência. Gerência de educação, cultura e lazer. São Paulo: Funap, 1990 [mimeografado].

ONU. Regras mínimas da Organização das Nações Unidas sobre prevenção de delito e tratamento de reclusos. Publicada e distribuída pelo Sindicato dos Funcionários do Sistema Prisional do estado de São Paulo, julho, 1998.

SÃO PAULO. Programa Estadual de Direitos Humanos. Imprensa Oficial, 1997.

SECRETARIA DE ESTADO DA EDUCAÇÃO / CENTRO DE EXAMES SUPLETIVOS. Conteúdos Programáticos dos Exames de Suplência - Educação Geral - 1ํograu. São Paulo: Imesp, 1989.

Recebido em 16.10.01

Aprovado em 05.12.01

Manoel Rodrigues Portugues é mestre em educação pela Faculdade de Educação da Universidade de São Paulo e integrante da equipe de coordenação dos programas de educação e cultura do Sistema Penitenciário do Estado de São Paulo (Fundap). 